\title{
Canadian Society of Plastic Surgeons Strategic Planning 2014: Plotting the way ahead
}

\author{
W Bryan Callaghan MD FRCSC
}

$P^{\prime}$ lastic Surgery is the official journal of the Canadian Society of Plastic Surgeons (CSPS). One of the Journal's fundamental roles is communication to members of important information regarding the practice of plastic surgery. In this regard, changes in vision and direction of the CSPS would be of paramount importance to all members, current and future. In June 2014, the CSPS embarked on a strategic planning day to determine the activities and direction of the society over the next three to five years. Dr Bryan Callaghan, president of the CSPS at that time, chaired the meeting and has graciously summarized the salient findings of the meeting. Please take time to read, contemplate and respond to the article.

Sincerely, Edward W Buchel MD Editor-in-Chief

\section{DETERMINING THE NEED}

At the November 2013 meeting of the Board of the CSPS, an important introspective discussion occurred that raised many questions surrounding the value of the Society to its members. Was the CSPS providing engagement opportunities and information that made it important for Canadian plastic surgeons to be members? Was the CSPS listening to its members and aware of their needs? What really is expected of the organization in the coming years?

Quickly, it becomes apparent that the CSPS, as a not-for-profit professional organization, needs to deliver value to the members if we are to remain competitive with other professional societies and continue to attract and retain new members. To accomplish that, we must try to better understand their needs.

What followed at that time was a unanimous decision by the Board to convene a Strategic Planning working group, to meet June 23, 2014, before the annual meeting in Montreal, Quebec. This would bring together, for a half-day, a selection of present, past and future leadership of the CSPS. Under the guidance of an experienced professional facilitator, this group would work toward an updated strategic plan.

STRATEGIC PLANNING DAY: JUNE 23, 2014

To speak of a 'new' strategic plan was to recognize that it would build on the decades of work by leaders who have kept the CSPS viable and relevant for Canadian plastic surgeons since 1947. Instead, an 'updated' plan was the goal - a template to guide the activities of the Society over the next three to five years.

The invited participants represented all regions of the country and the full range of career stages. What they all shared in common was a proven interest in the activities of the CSPS and a demonstrated role in its leadership. Each individual voluntarily added an extra day to the schedule of the annual meeting in Montreal and travelled one day early to participate.

Mr Frank Byrnes, President of Human Potential Consultants Inc (Newmarket, Ontario), was selected as our facilitator. His work began weeks before the session when he sent out a questionnaire collecting some important background information from each participant. This collection of challenges, strengths and desired outcomes from each participant not only informed Mr Byrnes of how we see ourselves at CSPS, but also was shared among the entire group in an anonymous format. This valuable sharing of ideas and perceptions enabled the working group to 'hit the ground running' for the strategic planning exercise. Everyone had something to contribute.

\section{WHAT DID WE LEARN?}

To summarize the input from the prequestionnaires, the responses were presented under three broad headings:

\section{'Working Well'}

- Organizational structure with superb administrative support, a cohesive collegial membership and responsible leadership.

- A well-attended and planned annual meeting widely appreciated by members as well as residents and guests.

- A membership reflecting the age and gender mix in the profession; collegiality where shared common goals override subspecialty interests.

- Year-to-year operations that defend our domain among competing specialties and keep members involved through committee responsibilities.

'Challenges'

- Need for a communications strategy for marketing, public relations, branding and lobbying with governments and hospitals/universities.

- Improvements to the annual meeting with better use of polling information to adjust content and structure

- Deeper administrative support strength; assistant for ED/CEO.

- Adding value for the members and engaging our stakeholders.

- Workforce issues and engaging the younger members.

'Desired Outcomes'

- A vision and direction that will respond to members' needs.

- Continued improvement of our educational events informed by member input from annual meetings.

- A voice for the specialty of plastic surgery in resource allocation and workforce planning.

- A plan to assist the specialty to measure and manage risk (external threats).

\section{WHAT WAS THE RESULT?}

During the working exercise. small breakout groups were used in a variety of combinations, interspersed with plenary reporting and discussion sessions. Remarkably, at what Frank Byrnes characterized as 'warp speed', a barrage of ideas and suggestions quickly evolved to a consensus opinion on five strategic goals. Hours of debate regarding our values were finally distilled into these elements of an updated strategic plan:

1. A focus on public relations to include the retention of external expert assistance in building a communications function at CSPS through multiple channels (web portal, mobile apps, social media, digital video, print media, etc). 
2. Education Committee restructuring with an expanded role to bolster the annual meeting planning (previously Program Committee) of scientific educational content.

3. Engage young plastic surgeons more actively in CSPS operations, building on the early positive feedback from the recent annual meetings.

4. Continual improvement of the annual meeting to better meet the educational needs and expectations of all members whether academic or community based, and reaching all stages of career.

5. Clarify the administrative capacity and needs of the CSPS, with a view toward increasing depth of support and managing critical talent risk.

\section{IMPLEMENTATION - AN ACTION PLAN}

The working group was extremely enthusiastic throughout the exercise, explaining how so much was achieved in a matter of hours. The overarching sentiment was that this should all be repeated on a recurring basis, perhaps every three years.
So that no one strategic goal should override the others, each has been matched with a Board member who will recruit whatever support teams are necessary to keep the goals evolving to defined strategic objectives. With better clarity of our vision, each Strategy 'Captain' will report at the November 2014 Board meeting how these plans will be linked with the budget to create a new operational framework.

It promises to be a time of change and only the feedback from the membership will provide the evidence to validate whether the Strategic Planning Day was time well spent.

W Bryan Callaghan MD FRCSC Past President Canadian Society of Plastic Surgeons 